This item was submitted to Loughborough's Research Repository by the author.

Items in Figshare are protected by copyright, with all rights reserved, unless otherwise indicated.

\title{
Gel cast foam diesel particulate filters
}

PLEASE CITE THE PUBLISHED VERSION

PUBLISHER

(C) Trans Tech

LICENCE

CC BY-NC-ND 4.0

REPOSITORY RECORD

Binner, J.G.P., Steven W. Hughes, and Rodney M. Sambrook. 2007. "Gel Cast Foam Diesel Particulate Filters". figshare. https://hdl.handle.net/2134/2682. 


\section{Loughborough University}

This item was submitted to Loughborough's Institutional Repository by the author and is made available under the following Creative Commons Licence conditions.

\section{(c) creative

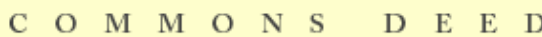

Attribution-NonCommercial-NoDerivs 2.5

You are free:

- to copy, distribute, display, and perform the work

Under the following conditions:

BY Attribution. You must attribute the work in the manner specified by the author or licensor.

mercial You may not use this work for commercial purposes.

No Derivative Works. You may not alter, transform, or build upon this work.

- For any reuse or distribution, you must make clear to others the license terms of this work.

- Any of these conditions can be waived if you get permission from the copyright holder.

Your fair use and other rights are in no way affected by the above.

This is a human-readable summary of the Legal Code (the full license).

Disclaimer 민

For the full text of this licence, please go to: http://creativecommons.org/licenses/by-nc$\underline{\mathrm{nd} / 2.5 /}$ 


\title{
Gel Cast Foam Diesel Particulate Filters
}

\author{
J.G.P. Binner ${ }^{1}$, S. Hughes ${ }^{1}$ and R.M. Sambrook ${ }^{2}$ \\ ${ }^{1}$ IPTME, Loughborough University, Loughborough, UK, ${ }^{2}$ Dytech Corporation Ltd, Dronfield, UK
}

Keywords: Ceramic foams, diesel particulate trap, gel casting.

\begin{abstract}
A new manufacturing route for foam ceramics based on gel casting has been developed and is being commercialised. Gel casting employs an organic monomer that is polymerised to cause the insitu gelation of a foamed aqueous ceramic slurry. The primary advantage is the inherent flexibility of the process; the foams can be near net shape manufactured in a variety of shapes and sizes and after production are simply dried and fired. In addition, the porosity and pore size distribution can be varied to suit the application and a wide range of ceramics can be foamed with densities ranging from 5-40\% of theoretical. Applications are diverse and include the potential to be used as diesel particulate filters (DPF). The present work examines this and concludes that filtration efficiencies of $\geq 90 \%$ are achievable without generating a significant backpressure for the engine.
\end{abstract}

\section{Introduction}

Diesel engines are becoming more popular on our roads thanks primarily to increased fuel economy compared to petrol engines and improved engineering allowing a reduction in the engine size. The diesel engine is also the main power source for the worlds' heavy transport industry in which it is unrivalled. Although it has many benefits, it also has a number of drawbacks; primarily its problematic emissions of nitrogen oxides $\left(\mathrm{NO}_{\mathrm{x}}\right)$ and diesel particulate matter (DPM). As a result worldwide legislation has been introduced in order to force a reduction in diesel exhaust pollutants and this has led to a variety of techniques, including engine and fuel modifications, being explored by manufacturers to try to meet the increasingly stringent emission regulations. One well tested and researched route for emissions reduction is through the use of after-exhaust treatment devices, for which a wide variety of technologies exist. One of the main methods employed is to use a diesel particulate trap to filter the exhaust stream. A number of different filtration systems have been examined, including the use of ceramic foam filters. They require a filtration efficiency $>80 \%$ and to maintain a low backpressure to avoid increased fuel consumption.

Any DPF system requires the removal of the trapped soot. Two strategies exist, passive and active. A number of technologies have been developed for both, however due to cost and reliability issues passive systems are preferred. One such method is the use of a catalytic coating that is active within the temperature window of the diesel exhaust gases, typically $300-500^{\circ} \mathrm{C}$, such that a "trapless trap" system can be achieved, i.e. the DPM is destroyed at the same rate that it is filtered.

\section{The Foaming Process}

The patented process for fabricating the ceramic foams, which has now been taken to full commercial status by Hi-Por Ceramics (http://www.hi-por.com/), is given by the flowchart in figure 1. A stable, well-dispersed, high solids content, aqueous ceramic suspension is prepared which also incorporates an acrylate monomer together with an initiator and catalyst. The latter is used to provide in-situ polymerisation. After the further addition of a foaming agent, a high shear mixer is used to provide simple mechanical agitation resulting in the formation of a wet ceramic foam. Variables include the degree of mechanical agitation and the pressure in the system. The latter affects the degree to which the bubbles formed can expand and hence can be used to control pore size if required.

One of the advantages of the method is that it is common to observe a period of inactivity between the addition of reagents and the beginning of the polymerisation reaction. This is known as the induction period or idle time $\left(\mathrm{t}_{\mathrm{i}}\right)$ and is beneficial since it allows the casting of the fluid foam into a mould prior to polymerisation and stabilisation of the foam structure. However, the induction period also allows time for bubble enlargement and lamella thinning. These can result in the presence of flaws 

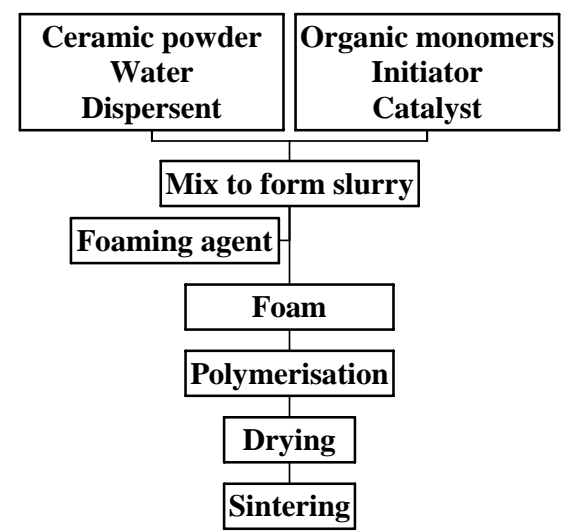

Fig. 1. Process flow chart for production of ceramic foams. in the cell walls if excessive disruption of the films occur before polymerisation takes place. Good control of the induction time is primarily achieved by altering the concentration of initiator and catalyst, although other parameters are also very important such as the temperature and $\mathrm{pH}$.

\section{Experimental and Results}

A series of ceramic foams of varying composition, density and cell size were produced using the gel cast process. Due to space considerations, details of the experimental procedure are omitted from this paper, however a description may be found in reference 1. The work to be described therefore focuses on two primary issues, an investigation into the filter performance of the ceramic foams and then the ability to regenerate the foams on a continuous basis using catalytic action.

Filter Performance. An experimental rig was constructed, fig 2, that allowed both the filtration efficiency and the back pressures generated to be monitored simultaneously.

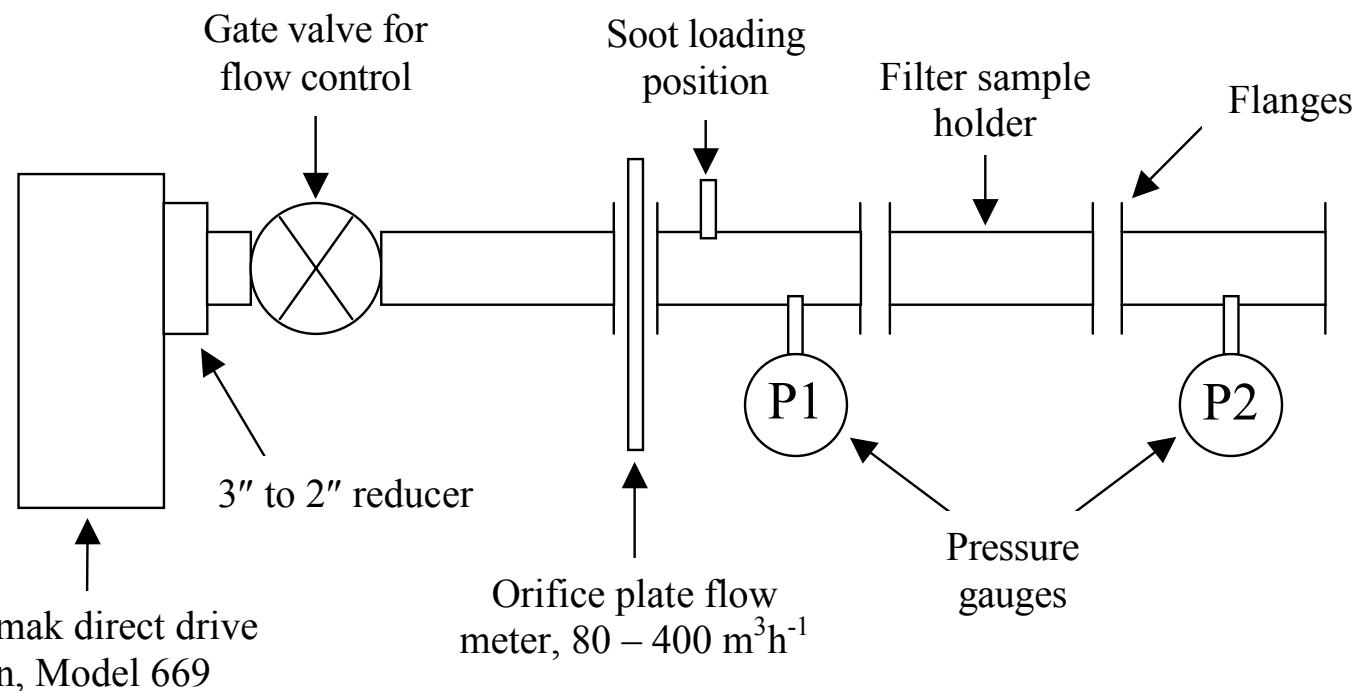

Figure 2: Schematic of the rig for measuring filtration efficiency and back pressure.

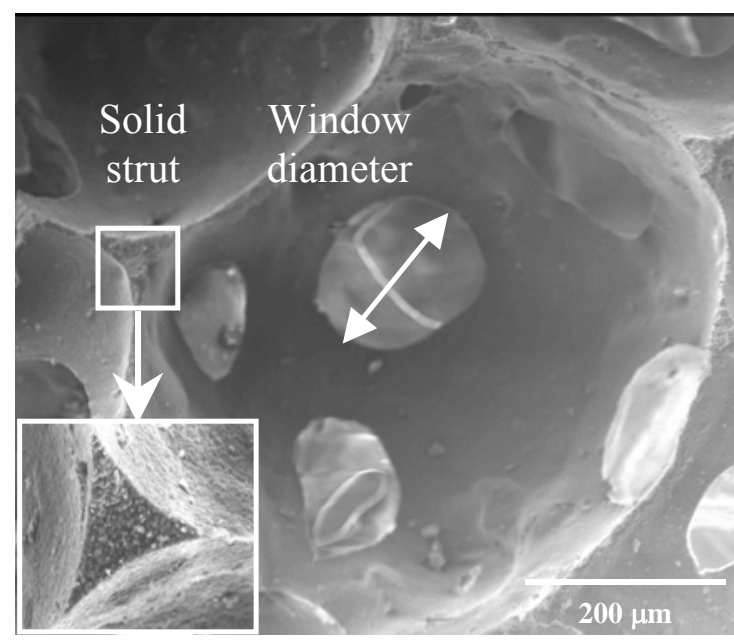

Fig. 3: Structure of the ceramic foams.
Dry Printex U model soot (Degussa, Germany) was fed in precise quantities into the system from where it was blown at a known velocity towards a sample filter of precisely known mass that was held in the sample holder by a system of O-rings that prevented any soot from escaping around the edges. Soot that passed through the filter was collected by a dust collection system at the rear of rig. The two pressure gauges, one before and one after the filter, allowed the pressure drop to be measured. After the end of each experiment the filter was removed extremely carefully and immediately weighed to determine the mass of soot that had been trapped. By also measuring the mass of soot that had been collected at the rear of the rig it was possible to calculate the efficiency of the filter. Note: Filter efficiencies were calculated from the masses of soot captured by the filter and the dust collection system, not from the mass of soot introduced since inevitably some stuck to the walls in the vicinity of 
the soot loading position. The foam filters investigated varied in terms of their length, density, cell and window size, see figure 3 below. Foam compositions included cordierite, mullite and alumina amongst other ceramic materials.

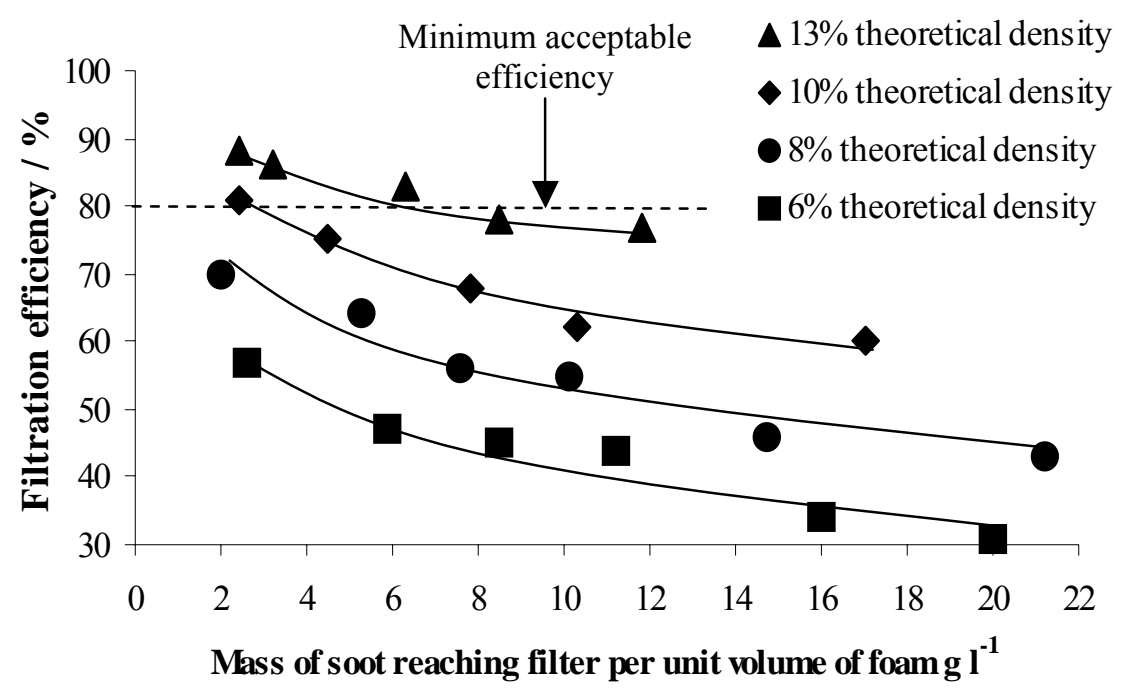

Fig. 4: Filtration efficiency of various density foams

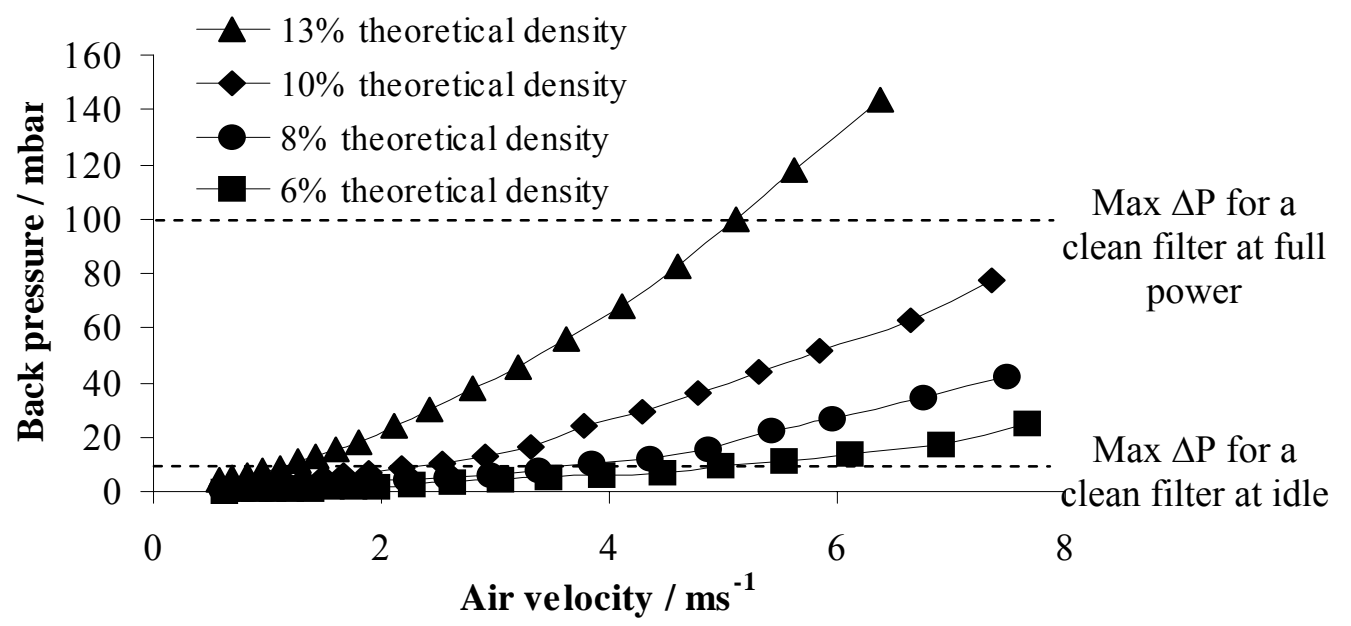

Fig. 5: Backpressures generated by various density foams

The gel cast ceramic foams have a structure that makes gas flow through them tortuous, a feature that provides a high filtration efficiency, figure 4, whilst the back pressure is low enough provided the density of the foam is kept low, figure 5. A linear relationship exists between the filter length and the resultant backpressure. It should be noted that Printex U, a commercial flame soot, was used as a simulant for real soot; this led to a decrease in filtration efficiency being observed in figure 4 with increasing soot mass reaching the front face of the foam. This is due to the Printex $U$ being extremely dry and so being blown off the filter by the momentum of the air flowing through it. This phenomenon does not occur when real engine soot is used.

Regeneration system. A wide range of different catalytic materials were developed and their activity for the combustion of the model diesel soot examined by measuring the weight loss versus temperature via thermo-gravimetric analysis (TGA). The results yielded three temperatures, the onset of soot oxidation $\left(\mathrm{T}_{\mathrm{ig}}\right)$, that at which the soot was completely oxidised $\left(\mathrm{T}_{\text {final }}\right)$ and the value for maximum combustion rate $\left(\mathrm{T}_{\max }\right)$, as well as the combustion rate of the soot.

Two different sample preparation techniques were used in order to provide samples in which the number of contact points between the catalyst and soot were at a maximum (known as 'tight contact') or were well below the maximum (known as 'loose contact'). The former was achieved by 
ball milling the soot and powdered catalytic material together for 2 hours so that they were well mixed, whilst loose contact involved brushing the catalyst and soot together through a $125 \mu \mathrm{m}$ sieve twice so that the constituents were poorly but repeatably mixed. This enabled the best and worst case scenarios in terms of catalytic activity to be evaluated. The $\sim 25$ materials examined were divided into four basic groups, simple oxides, spinel-type, perovskite-type and liquid forming catalysts. Space considerations prevent all of the results being presented here, however a small selection are illustrated in table 1 for tight contact conditions. It should be noted that for commercial reasons, the best materials evaluated are not identified. All the catalysts showed a worse performance when measured under loose contact conditions as expected.

\begin{tabular}{|c|c|c|c|c|}
\hline Catalyst & $\begin{array}{l}\mathbf{T}_{\max } \\
/{ }^{0} \mathbf{C}\end{array}$ & $\begin{array}{r}\mathbf{T}_{\mathrm{ig}} \\
/{ }^{0} \mathbf{C}\end{array}$ & $\begin{array}{l}\mathrm{T}_{\text {final }} \\
/{ }^{0} \mathrm{C}\end{array}$ & $\begin{array}{c}\mathbf{R}_{\max } \\
/ \mathbf{m g ~ m i n}^{-1}\end{array}$ \\
\hline $\mathbf{A l}_{2} \mathbf{O}_{3}$ (Uncatalysed) & 621.7 & 500 & 650 & 0.19 \\
\hline $\mathrm{CeO}_{2}$ & 569.6 & 440 & 590 & 0.28 \\
\hline $\mathrm{CoFe}_{2} \mathrm{O}_{4}$ & 580.5 & 407.2 & 615.0 & 0.12 \\
\hline $\mathrm{Cu}_{0.5} \mathrm{Co}_{0.5} \mathrm{Fe}_{2} \mathrm{O}_{4}$ & 505.2 & 413.8 & 540.5 & 0.35 \\
\hline $\mathrm{CuFe} \mathrm{Fe}_{2} \mathrm{O}_{4}$ & 488.1 & 406.2 & 518.6 & 0.64 \\
\hline $\mathrm{La}_{0.9} \mathrm{~K}_{0.1} \mathrm{CoO}_{3}$ & 478.6 & 336.7 & 520.5 & 0.19 \\
\hline $\mathrm{La}_{0.9} \mathrm{~K}_{0.1} \mathrm{FeO}_{3}$ & 461.5 & 321.0 & 485.3 & 0.13 \\
\hline $\mathbf{X}$ & 392.9 & 335.7 & 440.5 & \\
\hline $\mathbf{Y}$ & 374.2 & 313.1 & 402.0 & \\
\hline
\end{tabular}

Table 1: DTGA results for potential catalysts with Printex U under tight contact conditions.

The results showed that the highest activity was seen by materials that form liquid phases. These aid in the catalytic process by wetting the soot particulates thus providing a greater degree of contact. A number of perovskite and spinel type catalysts were shown to be active, although less than the above liquid phase types. The metal oxides all showed poor activity.

Further work undertaken on the best catalysts included an evaluation of their potential to be poisoned by sulphur, to react with the ceramic foam substrate and to withstand repeated thermal cycling. These results will be published elsewhere, however it may be stated that a system was found that suffered negligibly from poisoning, did not react with some substrates and could withstand thermal cycling up to the maximum number of cycles investigated to date.

\section{Conclusions}

A new, novel and very flexible manufacturing route for producing advanced ceramic foams has been invented, developed, patented and commercialised as a result of a collaboration between academia and industry in the UK. Foams have been made from a wide range of ceramic systems and the results indicate that provided a stable aqueous suspension can be produced it is possible to manufacture a useful foamed product. Densities range from 5\% to $40 \%$ of theoretical and the cell size is increasingly independent on the density of foam produced. The foams have been found to offer the potential to trap up to $\sim 90 \%$ of a model diesel soot without causing excessive backpressures for the engine. Investigations into the ability to use a catalytic system to produce a 'trapless trap' in which the soot is destroyed at the same rate as it is trapped have been relatively successful, although further work is still required to optimise the system.

\section{Acknowledgements}

The authors acknowledge Dytech Corporation Ltd, the original sponsors of the research and sister company to Hi-Por Ceramics, and the Engineering and Physical Sciences Research Council in the UK.

\section{References}

[1] P. Sepulveda and J.G.P. Binner, Journal of the European Ceramic Society, 19 2059-2066 (1999). 